\title{
The revised version of the screen for child anxiety related emotional disorders (scared-r): Further evidence for its reliability and validity
}

Citation for published version (APA):

Muris, P. E. H. M., Merckelbach, H. L. G. J., van Brakel, A. M. L., \& Maijer, B. N. (1999). The revised version of the screen for child anxiety related emotional disorders (scared-r): Further evidence for its reliability and validity. Anxiety Stress and Coping, 12(4), 411-425.

https://doi.org/10.1080/10615809908249319

Document status and date:

Published: 01/01/1999

DOI:

10.1080/10615809908249319

Document Version:

Publisher's PDF, also known as Version of record

Please check the document version of this publication:

- A submitted manuscript is the version of the article upon submission and before peer-review. There can be important differences between the submitted version and the official published version of record.

People interested in the research are advised to contact the author for the final version of the publication, or visit the DOI to the publisher's website.

- The final author version and the galley proof are versions of the publication after peer review.

- The final published version features the final layout of the paper including the volume, issue and page numbers.

Link to publication

\footnotetext{
General rights rights.

- You may freely distribute the URL identifying the publication in the public portal. please follow below link for the End User Agreement:

www.umlib.nl/taverne-license

Take down policy

If you believe that this document breaches copyright please contact us at:

repository@maastrichtuniversity.nl

providing details and we will investigate your claim.
}

Copyright and moral rights for the publications made accessible in the public portal are retained by the authors and/or other copyright owners and it is a condition of accessing publications that users recognise and abide by the legal requirements associated with these

- Users may download and print one copy of any publication from the public portal for the purpose of private study or research.

- You may not further distribute the material or use it for any profit-making activity or commercial gain

If the publication is distributed under the terms of Article 25fa of the Dutch Copyright Act, indicated by the "Taverne" license above, 


\title{
THE REVISED VERSION OF THE SCREEN FOR CHILD ANXIETY RELATED EMOTIONAL DISORDERS (SCARED-R): FURTHER EVIDENCE FOR ITS RELIABILITY AND VALIDITY
}

\author{
PETER MURIS $^{\mathrm{a}, *}$, HARALD MERCKELBACH ${ }^{\mathrm{a}}$, \\ ANNEKE VAN BRAKEL ${ }^{a}$ and BIRGIT MAYER ${ }^{b}$ \\ ${ }^{a}$ Department of Psychology, ${ }^{b}$ Department of Experimental Abnormal \\ Psychology, Maastricht University, P.O. Box 616. \\ 6200 MD Maastricht, The Netherlands
}

(Received in final form \& December 1998)

\begin{abstract}
The revised version of the Screen for Child Anxiety Related Emotional Disorders (SCARED-R) is a self-report questionnaire that intends to measure symptoms of childhood anxiety disorders as defined in the Diagnostic and Statistical Manual of Mental Disorders (DSM; American Psychiatric Association. 1994). The current article presents three studies which examined in more detail the reliability and validity of the SCAREDR. Study $1(N=101)$ demonstrated that the SCARED-R possesses satisfactory testretest stability. Study $2(N=71)$ shows that the child-parent agreement of the SCARED-R is rather low. Study $3(N=88)$ provides support for the concurrent validity of the SCARED-R. More specifically, SCARED-R scores were correlated in a meaningful way with scores on the Children's Anxiety Scale, a questionnaire that also measures DSM-defined childhood anxiety symptoms.
\end{abstract}

Keywords: Childhood anxiety disorders; Self-report questionnaire; Screen for Child Anxiety Related Emotional Disorders

Self-report questionnaires of childhood anxiety are widely employed in both clinical and research settings. This type of instrument is easy to administer, requires a minimum of time, and economically measures

* Corresponding author. E-mail: p.muris@ psychology.unimaas.nl. 
anxiety symptoms from the child's point of view (Strauss, 1993). The most widely used questionnaires for assessing anxiety in children are the State-Trait Anxiety Inventory for Children (STAIC; Spielberger, 1973), the Children's Manifest Anxiety Scale (CMAS; Reynolds and Richmond, 1978), and the Fear Survey Schedule for Children (FSSC; Ollendick, 1983). Although these scales are reliable and informative measures of childhood anxiety, they all provide a global unidimensional index of anxiety. As a result, they are not keyed to the separate anxiety disorders as listed in the fourth edition of the Diagnostic and Statistical Manual of Mental Disorders (DSM-IV; American Psychiatric Association [APA], 1994).

Over the past few years, several attempts have been made to develop multidimensional questionnaires for measuring childhood anxiety symptoms. One example is the Children's Anxiety Scale (CAS; Spence, 1997; 1998), which taps symptoms of a number of DSM-defined anxiety disorders, namely panic disorder, separation anxiety disorder, social phobia, obsessive-compulsive disorder, and generalized anxiety disorder. Furthermore, the CAS contains a physical injury fears scale representing the DSM-category of specific phobias.

Another recently developed measure is the Screen for Child Anxiety Related Emotional Disorders (SCARED; Birmaher et al., 1997). This questionnaire also intends to measure DSM-defined anxiety disorder symptoms. The original SCARED contains 38 items that can be allocated to five separate anxiety subscales. Four of these subscales represent anxiety disorders corresponding to DSM-categories, namely panic disorder, generalized anxiety disorder, social phobia, and separation anxiety disorder. The fifth scale is school phobia which, according to Birmaher et al. (1997), can best be considered as a separate anxiety category. Muris and colleagues (Muris et al., 1999) revised the SCARED in three ways. To begin with, school phobia items were assigned to the separation anxiety disorder subscale. This was done because the DSM-IV views school phobia as a symptom of separation anxiety disorder. Secondly, 15 new items were added in an attempt to cover the main types of specific phobia (i.e., animal phobia, environmental-situational phobia, and blood-injection-injury phobia). Thirdly, although obsessive-compulsive disorder and traumatic stress disorder are relatively rare, an extra 13 items were added so that it became possible to tap symptoms of these disorders. Thus, the final 
66-item revised version of the SCARED (i.e., SCARED-R) intends to measure the symptoms of the entire anxiety disorders spectrum that, according to the DSM-IV, may occur in children.

So far, a number of studies have examined the reliability and validity of the SCARED-R. The results of these studies can be catalogued as follows. First of all, the SCARED-R seems to be a reliable instrument in terms of internal consistency (see e.g., Muris et al., 1999). Furthermore, evidence has accumulated for the concurrent validity of the SCARED-R. That is, SCARED-R scores positively correlated with scores on traditional anxiety scales (e.g., STAIC, CMAS, and FSSC; see Muris et al., 1998c; 1998e), with the internalizing problem scale of the Child Behavior Checklist (Muris et al., 1998d), and with measures of negative self-statements (Muris et al., 1998b) and depression (Muris et al., 1998e). Finally, support has been found for the discriminant validity of the SCARED-R. More specifically, there is evidence that the SCARED-R satisfactorily discriminates children with a specific anxiety disorder from children without that particular anxiety disorder (Muris et al., in press).

The current article describes three studies, all relying on independent samples of children that further examined the reliability and validity of the SCARED-R. In the first study, the test-retest stability of the SCARED-R was investigated. In the second study, child-parent agreement of the SCARED-R was examined. In the third and final study, SCARED-R scores were validated against the CAS (Spence, 1997; 1998), which also measures childhood anxiety symptoms in terms of the DSM-IV.

\section{STUDY 1: TEST-RETEST STABILITY}

\section{Method}

A sample of 101 children ( 47 boys and 54 girls) recruited from regular secondary schools completed the SCARED-R twice, 12 weeks apart. This was done at school during classes in the presence of a research assistant. Children had a mean age of 12.2 years $(S D=0.5$, range $11-$ 14 years).

The SCARED- $R$ is a 66 -item self-report questionnaire measuring symptoms of panic disorder ( 13 items; e.g., "When frightened, my heart 
beats fast"), generalized anxiety disorder ( 9 items; e.g., "I worry about things working out for me"), social phobia (4 items; e.g., "I don't like to be with people I don't know"), separation anxiety disorder (12 items; e.g., "I don't like being away from my family"), obsessive-compulsive disorder (9 items; e.g., "I have thoughts that frighten me"), traumatic stress disorder (4 items; e.g., "I have frightening dreams about a very aversive experience I once had"), specific phobia - animal type (3 items; e.g., "I am afraid of an animal that is not really dangerous"), specific phobia - blood-injection-injury type (7 items; e.g., "I am afraid to go to the dentist"), and specific phobia - environmentalsituational type (5 items; e.g., "I am scared to fly in an airplane"). Children indicate how frequently they experience each symptom on a three-point scale: almost never, sometimes, or often. These are scored 0 , 1 , and 2, respectively. SCARED-R total score and subscale scores can be obtained by summing across relevant items.

\section{Results}

The results of Study I replicate the satisfactory internal consistency of the SCARED-R reported earlier (e.g., Muris et al., 1999; see left columns of Table I). Furthermore, in Study 1, no significant associations between age and SCARED-R scales were found.

Table II shows mean SCARED-R scores on both occasions for the total sample, and for boys and girls separately. A series of 2 (Gender) $\times 2$ (Occasion) analyses of variance with the last factor being

TABLE I Internal consistency coefficients (Cronbach's alphas) for the various SCARED-R scales in Studies 1, 2, and 3

\begin{tabular}{lcccccc}
\hline SCARED-R & \multicolumn{2}{c}{ Study 1 } & & \multicolumn{2}{c}{ Study 2 } & \multirow{2}{*}{ Study 3 } \\
\cline { 2 - 3 } & Occasion 1 & Occasion 2 & & Child & Parent & \\
\hline Total score & 0.91 & 0.91 & & 0.92 & 0.92 & 0.92 \\
Panic disorder & 0.82 & 0.81 & & 0.83 & 0.76 & 0.82 \\
Generalized anxiety disorder & 0.80 & 0.77 & & 0.79 & 0.82 & 0.78 \\
Social phobia & 0.71 & 0.78 & & 0.70 & 0.84 & 0.71 \\
Separation anxiety disorder & 0.60 & 0.68 & & 0.76 & 0.74 & 0.75 \\
Obsessive-compulsive disorder & 0.60 & 0.65 & & 0.66 & 0.54 & 0.62 \\
Animal phobia & 0.87 & 0.86 & & 0.83 & 0.89 & 0.80 \\
Blood-injection-injury phobia & 0.67 & 0.68 & & 0.69 & 0.75 & 0.70 \\
Environmental-situational phobia & 0.60 & 0.58 & & 0.74 & 0.57 & 0.72 \\
Traumatic stress disorder & 0.70 & 0.70 & & 0.74 & 0.81 & 0.75 \\
\hline
\end{tabular}

SCARED-R = Screen for Child Anxiety Related Emotional Disorders - Revised. 


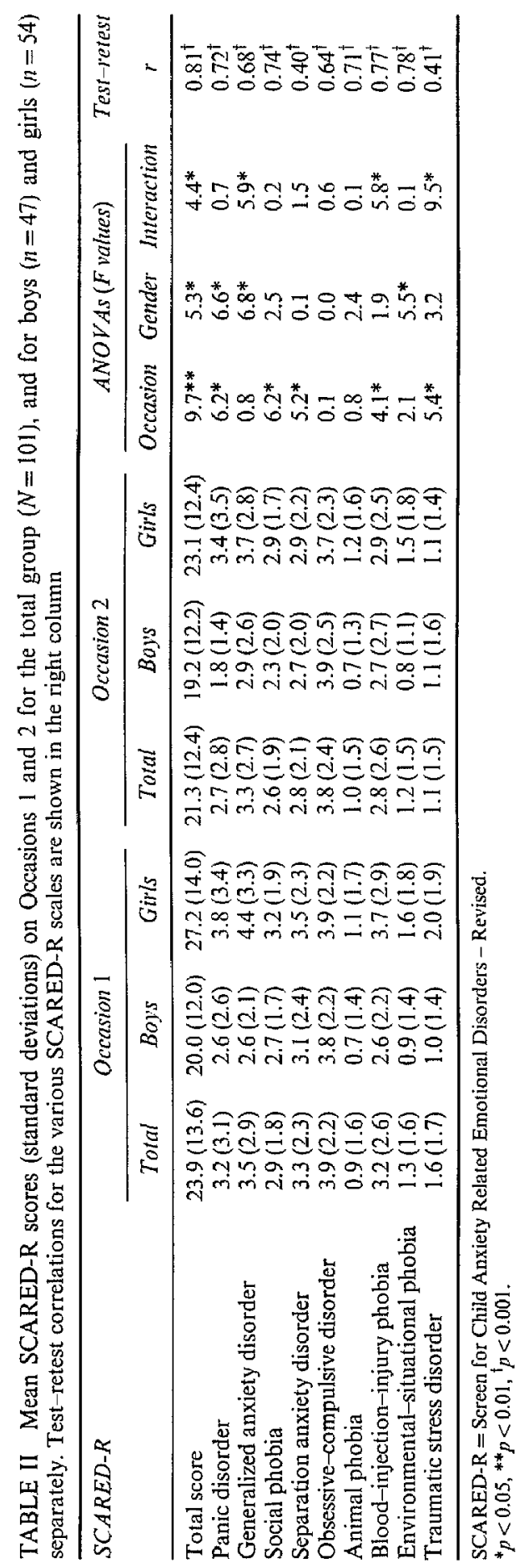


a repeated measure was carried out on these data. The results of these analyses can be summarized as follows. First of all, significant main effects of occasion were found for SCARED-R total score, panic disorder, social phobia, separation anxiety disorder, traumatic stress disorder, blood-injection-injury phobia. As can be seen in Table II, children's reports of these anxiety symptoms slightly decreased from Occasion 1 to Occasion 2. Furthermore, significant gender effects emerged for SCARED-R total score, panic disorder, generalized anxiety disorder, and environmental-situational phobia. In all of these cases, girls had higher levels of anxiety symptoms than boys. Finally, some of the analyses revealed a significant interaction of gender and occasion. Inspection of Table II indicates that this result was due to the fact that, in boys, the level of anxiety symptoms remained relatively stable, whereas in girls a decrease of anxiety symptoms was observed.

Test-retest correlations for the various SCARED-R scales are shown in the right column of Table II. As can be seen, the test-retest correlation was $0.81(p<0.001)$ for the SCARED-R total score, while test-retest correlations varied between $0.40 \quad(p<0.001$; separation anxiety disorder) and 0.78 ( $p<0.001$; environmental-situational phobia) for separate subscales. Altogether, although anxiety scores tended to decline from Occasion 1 to Occasion 2, these results underline that the SCARED-R possesses adequate test-retest reliability.

\section{STUDY 2: CHILD-PARENT AGREEMENT}

\section{Method}

One hundred and four children attending regular primary schools and their parents were contacted and asked to participate in Study 2. Ninety children and their parents agreed to participate. The children completed the SCARED-R in their classrooms in the presence of the teacher and a research assistant. Parents were visited at home and asked to complete the parent version of the SCARED-R. Eventually, complete SCARED-R data were obtained from 71 children (36 boys and 35 girls) and their parents. Mean age of the children was 9.6 years ( $S D=1.1$, range $8-12$ years). In more than $90 \%$ of the cases, the 
mother completed the parent version of the SCARED-R. In other cases, the SCARED-R was filled in by the father or by both parents.

The parent version of the SCARED-R is identical to the child version, except that items are rephrased in terms of the parents' perspective. Examples are "When my child is frightened, his/her heart beats fast", "My child worries about things working out for him/her", and "My child does not like to be with people he/she does not know".

\section{Results}

Statistical analysis revealed that both the child and the parent version of the SCARED-R generally were reliable in terms of internal consistency (see Table I). Furthermore, age appeared to be negatively associated with SCARED-R scores. More specifically, the correlation between age and SCARED-R total score was $-0.45(p<0.001)$ for the child version and $-0.20(p<0.10)$ for the parent version. Such effects were also found for separation anxiety disorder $(r=-0.48$, $p<0.001$ and $r=-0.24, p<0.05$, respectively), blood-injection-injury phobia $(r=-0.40, p<0.005$ and $r=-0.24, p<0.05)$, and environmental-situational phobia $(r=-0.47, p<0.001$ and $r=-0.34$, $p<0.005$ ).

Table III displays mean scores on the child and the parent version of the SCARED-R for the total group, and for boys and girls separately. A series of 2 (Gender) $\times 2$ (Assessor: Child/Parent) analyses of variance with the last factor being a within-subject factor revealed significant child-parent differences for SCARED-R total score, panic disorder, generalized anxiety disorder, separation anxiety disorder, obsessive-compulsive disorder, traumatic stress disorder, and environmental-situational phobia. As can be seen, children's scores were generally higher than parents' scores. Furthermore, although girls exhibited somewhat higher scores on the child version of the SCARED-R than boys, no significant gender effects were found.

The child-parent correlation corrected for age was $0.30(p<0.05)$ for the SCARED-R total score. For separate subscales, correlations varied between 0.03 (non-significant; generalized anxiety disorder) and $0.56(p<0.01$; environmental-situational phobia). Note that these figures come close to those reported by Birmaher et al. (1997) for the original SCARED. 


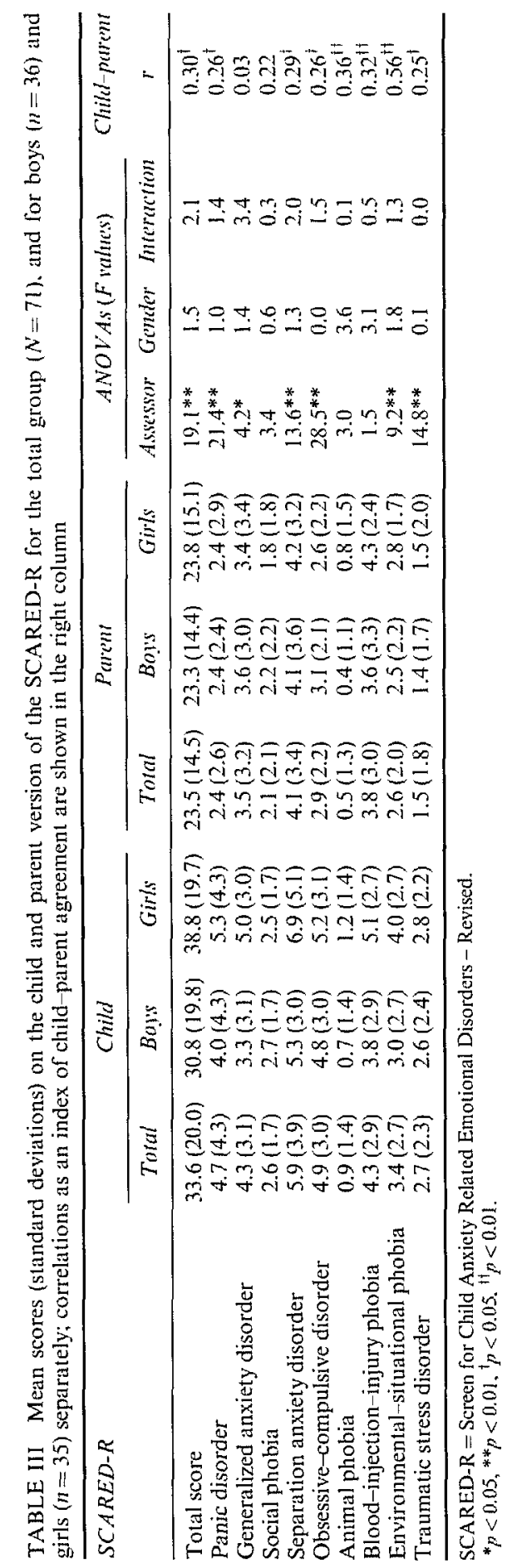


Altogether, these results are well in line with previous studies which found that child-parent correlations for anxiety symptoms are low and that parents generally underreport the frequency of these symptoms in their children (e.g., Rapee et al., 1994). There are reasons to believe that children with internalizing symptoms (e.g., anxiety symptoms) provide a better picture of the frequency of such symptoms than their parents (Stallings and March, 1995).

\section{STUDY 3: CONCURRENT VALIDITY}

\section{Method}

A sample of 88 children ( 54 boys and 34 girls) recruited from regular primary schools completed the SCARED-R and the CAS (Spence, 1997; 1998). This was done in their classrooms in the presence of their teacher and a research assistant. Children had a mean age of 10.0 years ( $S D=1.2$, range 8-12 years).

As already mentioned above, the CAS is a concurrent measure of the SCARED-R in that it follows the DSM-IV taxonomy of childhood anxiety disorders. The 38 items of the CAS tap the following anxiety disorders: panic disorder and agoraphobia (9 items; e.g., "All of a sudden I feel really scared for no reason at all", "I feel scared if I have to travel in the car, or on a bus or a train"), generalized anxiety disorder (6 items; e.g., "I worry that something bad will happen"), social phobia ( 6 items; e.g., "I feel a fraid that I will make a fool of myself in front of people"), separation anxiety disorder (6 items; e.g., "I feel scared if I have to sleep on my own"), obsessive-compulsive disorder (6 items; e.g., "I have to think of special thoughts to stop bad things from happening"), and physical injury fears (replacing specific phobias; 5 items; e.g., "I am scared of dogs"). Items are evaluated on a four-point scale; never, sometimes, often, or always. These are scored $0,1,2$, and 3 , respectively. CAS total and subscale scores can be computed by summing scores on relevant items.

\section{Results}

Both questionnaires appeared to be reliable in terms of internal consistency. For the SCARED-R, Cronbach's alphas are shown in the 
right column of Table I. For the CAS, these figures were 0.94 for the total scale, 0.82 for panic disorder and agoraphobia, 0.79 for generalized anxiety disorder, 0.76 for social phobia, 0.80 for separation anxiety disorder, 0.69 for obsessive-compulsive disorder, and 0.60 for physical injury fears.

A series of one-way analyses of variance revealed significant gender differences for SCARED-R separation anxiety disorder, SCARED-R animal phobia, CAS total score, CAS separation anxiety disorder, and CAS physical injury fears (see right column of Table IV). In all cases, girls had higher symptom levels than boys. Additionally, significant negative associations emerged between age, on the one hand, and most of the SCARED-R and CAS scales, on the other hand. For example, age correlated $-0.44, p<0.001$ with SCARED-R total score and $-0.39, p<0.001$ with CAS total score.

Table $\mathrm{V}$ shows correlations (corrected for gender and age) between SCARED-R and CAS scales. As can be seen, there was a robust correlation between the total scores of both scales: $r=0.88, p<0.001$. Furthermore, the correlations between SCARED-R subscales and their

TABLE IV Mean scores (standard deviations) on the SCARED-R and the CAS for the total group $(N=88)$, and for boys $(n=54)$ and girls $(n=34)$ separately

\begin{tabular}{lcccc}
\hline & Total & Boys & Girls & Fvalues Gender \\
\hline SCARED-R & & & & \\
Total score & $34.4(20.0)$ & $31.6(20.0)$ & $38.9(19.6)$ & 2.8 \\
Panic disorder & $4.9(4.3)$ & $4.4(4.2)$ & $5.8(4.4)$ & 2.1 \\
Gencralized anxiety disorder & $4.8(4.8)$ & $4.4(5.5)$ & $5.5(3.3)$ & 1.1 \\
Social phobia & $2.6(1.7)$ & $2.5(1.7)$ & $2.6(1.6)$ & 0.1 \\
Separation anxiety disorder & $6.1(3.9)$ & $5.4(3.0)$ & $7.1(5.0)$ & $4.3^{*}$ \\
Obsessive-compulsive disorder & $5.1(2.9)$ & $4.9(2.9)$ & $5.4(3.0)$ & 0.7 \\
Animal phobia & $0.8(1.3)$ & $0.6(1.3)$ & $1.1(1.3)$ & $4.2^{*}$ \\
Blood-injection-injury phobia & $4.3(2.9)$ & $4.0(3.0)$ & $4.7(2.6)$ & 1.5 \\
Environmental-situational phobia & $3.2(2.6)$ & $2.8(2.6)$ & $3.8(2.6)$ & 2.8 \\
Traumatic stress disorder & $2.7(2.3)$ & $2.6(2.3)$ & $2.8(2.2)$ & 0.1 \\
& & & & \\
CAS & & & & $4.0^{*}$ \\
Total score & $22.0(15.7)$ & $19.4(15.7)$ & $26.1(15.0)$ & 1.3 \\
Panic disorder and agoraphobia & $4.0(4.1)$ & $3.6(4.0)$ & $4.6(4.2)$ & 2.6 \\
Generalized anxiety disorder & $4.6(3.1)$ & $4.2(3.3)$ & $5.3(2.6)$ & 3.3 \\
Social phobia & $3.6(3.0)$ & $3.1(3.1)$ & $4.3(2.8)$ & $5.6^{*}$ \\
Separation anxiety disorder & $3.5(3.3)$ & $2.9(2.7)$ & $4.5(3.9)$ & 0.0 \\
Obsessive-compulsive disorder & $3.2(2.6)$ & $3.2(2.9)$ & $3.2(2.2)$ & $10.3^{* *}$ \\
Physical injury fears & $3.0(2.6)$ & $2.4(21)$ & $4.1(3.0)$ & \\
\hline
\end{tabular}

SCARED-R = Screen for Child Anxiety Related Emotional Disorders - Revised.

$\mathrm{CAS}=$ Children's Anxiety Scale.

${ }^{*} p<0.05,{ }^{* *} p<0.01$. 


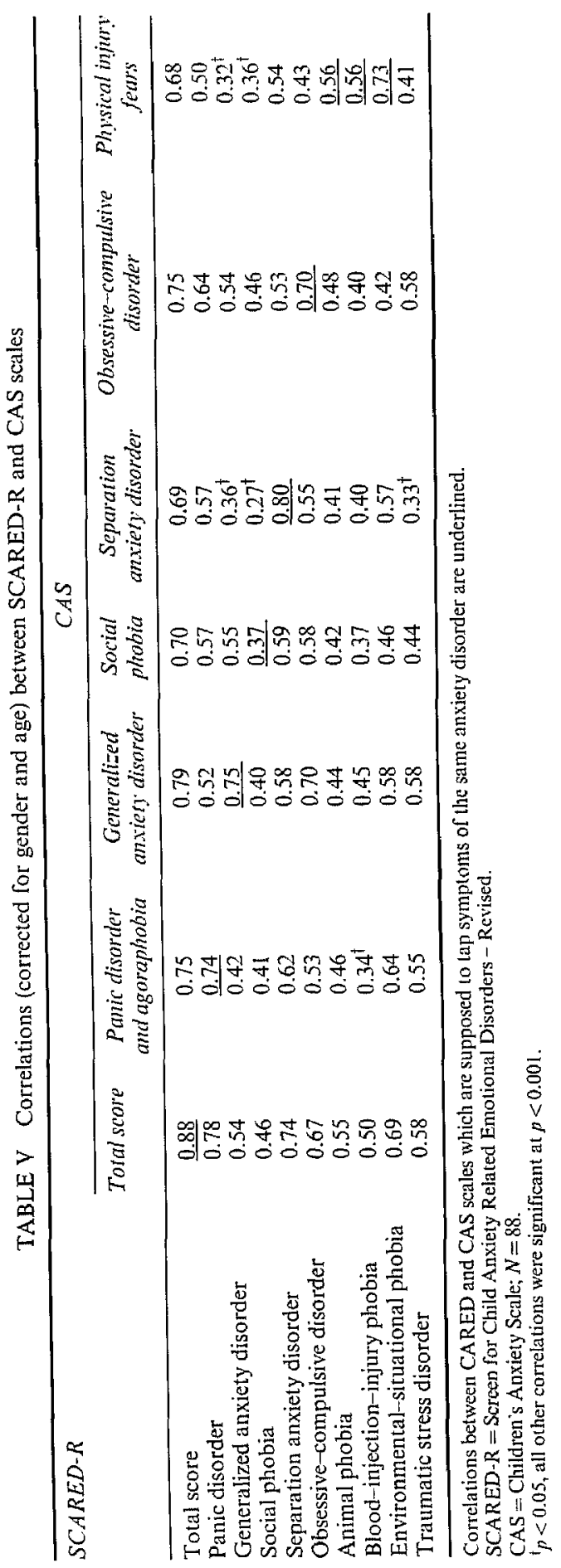


CAS counterparts were generally substantial. Thus, SCARED-R panic disorder was strongly associated with CAS panic disorder, SCARED-R generalized anxiety disorder with CAS generalized anxiety disorder, and so on. There was one exception to this pattern. The correlation between SCARED-R social phobia and its CAS counterpart was modest $(r=0.37, p<0.001)$. Inspection of item content revealed that both scales seem to tap a somewhat different aspect of social anxiety. Whereas the SCARED-R social phobia scale focuses on children's inhibition to meet unfamiliar persons (e.g., "I don't like to be with people I don't know", "I am shy with people I don't know well"), the CAS social phobia scale is more directed at performance fear (e.g., "I feel scared when I have to take a test", "I worry that I will do badly at my schoolwork") and fear of negative evaluation (e.g., "I feel afraid that I will make a fool of myself in front of others", "I worry what other people think of me"). To establish the relative merits of the SCARED-R and SCAS social phobia subscales in detecting social phobia, future studies relating both social phobia subscales to specific measures of social phobia (e.g., the Social Phobia Anxiety Inventory for Children; Beidel et al., 1995) are clearly warranted.

All in all, the results of Study 3 provide further support for the concurrent validity of the SCARED-R. That is, the scale not only correlates positively with traditional measures of childhood anxiety (i.e., STAIC, CMAS, and FSSC; Muris et al., 1998c; 1998e), but also with recently developed questionnaires that are conceptually based on current nosologic anxiety constructs (see also Muris et al., 1998a).

\section{GENERAL DISCUSSION}

The current article presents three studies that further investigated the reliability and validity of the SCARED-R. Results indicate that the SCARED-R possesses adequate test-retest stability (Study 1) and excellent concurrent validity (Study 3 ). Furthermore, child-parent agreement appeared to be rather low (Study 2). In the conclusion of their review on the measurement of childhood anxiety, Stallings and March (1995) remark that "Reliable and valid instruments, which incorporate multiple domains and reporters, are necessary to enable researchers (and ultimately clinicians) to address the multiple faces of 
anxiety in young persons" (p. 141). Indeed, the SCARED-R seems to be one promising tool for such an endeavor.

At a more theoretical level, the current data replicate a number of findings that have been previously reported in the literature on childhood anxiety. To begin with, marked gender differences in anxiety symptoms were found in Study 1, but not in Study 2, while Study 3 had an intermediate position in this respect (i.e., gender differences were only evident on some anxiety subscales). Keeping in mind that Study 2 relied on relatively young children (mean age 9.6 years), whereas Study 1 relied on an older sample (mean age 12.2 years), this pattern fits nicely with the idea that there is a progressive divergence of men versus women in anxiety symptoms with increasing age (e.g., Craske, 1997).

Another finding that deserves some comment is the negative association between anxiety symptoms as indexed by the SCARED-R and age. In both Study 2 and Study 3, the negative correlation between age and anxiety symptoms was well above the 0.40 . This accords well with a number of studies that found a decline in anxiety and fear with increasing age (see for a review, Craske, 1997). Meanwhile, it is also obvious that this pattern is most evident for separation anxiety disorder and specific phobias. Again, the present findings further substantiate such variations in the longitudinal course of specific anxiety categories.

A third finding that is of interest concerns the relatively poor agreement between children's and parents' SCARED-R scores (Study 2). Obviously, parents may not be quite good guides to the anxiety symptoms in their children (see above). This is not surprising because a large number of anxiety symptoms are not readily observable. For example, how would a parent know that the child frequently worries about certain topics? Or how would a parent know that the child's heart beats faster at particular times? For this reason, it seems justified that clinicians who evaluate the severity of children's anxiety symptoms should primarily rely on children's report of anxiety symptoms. Note that the unreliability of parental reports is a consistent theme emerging from several studies that compared children's and parents' report (e.g., Brewin et al., 1993). This point may seem self-evident, but becomes extremely relevant for evaluating studies relying on parental reports of children's fears and their antecedents (e.g., King et al., 1997). 
Two limitations of the present studies should be acknowledged. First of all, the sample sizes of the three studies were relatively small. Second, the studies relied solely on regular children in the community. It would be worthwhile to examine whether the present results are generalizable to clinically referred children.

In her recent review, Craske (1997; p. 4) noted that "relatively little attention has been paid to fear and anxiety in youths". Clearly, this research area would profit from reliable, valid, and easy-to-administer screening instruments. The present studies show that the SCARED-R fulfills these criteria and, thus, may be a valuable tool for more systematic research in this area.

\section{References}

American Psychiat ric Association (APA, 1994). Diagnostic and statistical manual of mental disortlers (4th edn.). Washington, DC: American Psychiatric Association.

Beidel, D.C., Turner, S.M. and Morris, T.L. (1995). A new inventory to assess childhood social anxiety and phobia: The Social Phobia and Anxicty Inventory for Children. Psychological Assessment, 7, 73-79.

Birmaher, B., Khetarpal, S., Brent, D., Cully, M., Balach, L., Kaufman, J. and McKenzie Neer, S. (1997). The Screen for Child Anxiety Related Emotional Disorders (SCARED): Scale construction and psychometric charactcristics. Journal of the American Academy of Child and Adolescent Psychiatry, 36, 545-553.

Brewin, C.R., Andrews, B. and Gotlib, I.H. (1993). Psychopathology and early experience: A reappraisal of retrospective reports. Psychological Bulletiin, 113, 82-98.

Craske, M.G. (1997). Fear and anxiety in children and adolescents. Bulletin of the Menninger Clinic, 61 (Suppl. A), A4-A36.

King, N.J., Clowes-Hollins, V. and Ollendick, T.H. (1997). The etiology of childhood dog phobia. Behaviour Research and Therapy, 35, 77.

Muris, P., Gadet, B., Moulaert, V. and Merckelbach, H. (1998a). Correlations between two multidimensional anxiety scales for children. Perceptual and Motor Skills, 87 $269,270$.

Muris, P., Merckelbach, H., Mayer, B. and Snieder, N. (1998b). The relationship between anxiety disorders symptoms and negative self-statements in normal children. Social Behavior and Personality, 26, 307-316.

Muris, P., Merckelbach, H., Mayer, B., Van Brakel, A., Thissen, S., Moulaert, V. and Gadet, B. (1998c). The Screen for Child Anxjety Related Emotional Disorders and its relationship to traditional childhood anxiety measures. Journal of Behavior Therapy and Experimental Psychiatry, 29, 327-339.

Muris, P., Merckelbach, H., MoulaerL, V. and Gadet, B. (1998d). Relationship between anxiety disorders symptoms and behavior problems in normal children (manuscript submitted for publication).

Muris, P., Merckelbach, H., Van Brakel, A., Mayer, B. and Van Dongen, L. (1998e), The Screen for Child Anxiety Related Emotional Disorders: Relationship with anxiety and depression in normal children. Personality and Individual Differences, 24, $451-456$.

Muris, P., Merckelbach, H., Mayer, B. and Prins, E. (in press). How serious are common childhood fears? Behaviout Research and Therapy. 
Muris, P., Merckelbach, H., Schmidt, H. and Mayer, B. (1999). The revised version of the Screen for Child Anxiety Related Emotional Disorders (SCARED-R): Factor structure in normal children. Pessonality and Individual Differences, 26, 99-112.

Ollendick. T.H. (1983). Reliability and validity of the Revised Fear Survey Schedule for Children (FSSC-R). Behaviour Researdh and Therapy, 23, 465-467.

Rapee, R.M., Barrett, P.M., Dadds, M.R. and Evans, I. (1994). Reliability of the DSM-III-R childhood anxiety disorders using structured interview: Interrater and parent-child agreement. Journal of the American Academy of Child and Adolescent Psychiatry, 33, 984-992.

Reynolds, C.R. and Richmond, B.O. (1978). What I think and feel: A revised measure of children's manifest anxiety. Jowrnal of Abnormal Child Psychology, 6, 271-280.

Spence, S.H. (1997). The structure of anxiety symptoms among children: A confirmatory factor analytic study. Journal of Abnormal Psychology, 106, 280-297.

Spence, S.H. (1998). A measure of anxiety symptoms among children. Behaviour Research and Therapy, 36, 545-566.

Spielberger, C.D. (1973). Manual for the State-Trait Antriety Inventory for Children. Palo Alto, CA: Consulting Psychologists Press.

Stallings, P. and March, J.S. (1995). Assessment. In J.S. March (Ed.), Anxiety disorders in children and adolescents. pp. 125-147. New York: Guilford.

Strauss, C.C. (1993). Anxiety disorders. In T.H. Ollendick and M. Hersen (Eds.), Handbook of child and adolescent assessment. pp. 239-250. Boston: Allyb \& Bacon. 